\title{
BMJ Open Prevalence of ocular fundus pathology with type 2 diabetes in a Chinese urban community as assessed by telescreening
}

Lei Liu, ${ }^{1,2,3}$ Jin Geng, ${ }^{1}$ Jingyang Wu, ${ }^{1}$ Zhe Yuan, ${ }^{1}$ Jie Lian, ${ }^{4}$ Huang Desheng, ${ }^{1,3}$ Lei Chen ${ }^{1,2}$

To cite: Liu L, Geng J, Wu J, et al. Prevalence of ocular fundus pathology with type 2 diabetes in a Chinese urban community as assessed by telescreening. BMJ Open 2014;3:e004146.

doi:10.1136/bmjopen-2013004146

- Prepublication history and additional material for this paper is available online. To view these files please visit the journal online (http://dx.doi.org/10.1136/ bmjopen-2013-004146).

Received 1 October 2013 Revised 27 November 2013 Accepted 29 November 2013

\section{CrossMark}

${ }^{1}$ Department of Ophthalmology, The First Hospital of China Medical University, Shenyang, China

${ }^{2}$ Key Laboratory of Endocrine Diseases in Liaoning Province, The First Hospital of China Medical University, Shenyang, China

${ }^{3}$ Department of Epidemiology, School of Public Health, China Medical University, Shenyang, China ${ }^{4}$ Healthcare Center of Fengyutan Community, Shenyang, China

Correspondence to Dr Lei Chen; carol1422@163.com

\section{ABSTRACT}

Objective: To describe the telescreening model and assess the prevalence of ocular fundus pathology in patients with type 2 diabetes within a Chinese urban community.

Design: Community-based cross-sectional study. Setting: Healthcare centre of Fengyutan Community, Shenyang, China.

Participants: A total 528 patients (287 females) with type 2 diabetes mellitus (DM) were randomly recruited using health files from the healthcare centre of Fengyutan community between 8 October and 20 November 2012.

Main outcome measures: Signs of any diabetic retinopathy (DR), signs of glaucoma and signs of age-related macular degeneration (AMD).

Results: The main ocular fundus pathologies were DR (75 patients, $14.20 \%), 65(86.67 \%)$ cases of which were newly detected, AMD (57 patients, 10.79\%) and glaucoma (63 patients, 11.93\%). The risk factors for fundus pathology were long duration of diabetes (OR 2.31, 95\% $\mathrm{Cl} 1.87$ to 2.56), and higher fasting plasma glucose (OR $3.64,95 \% \mathrm{Cl} 1.81$ to 5.21 ) and glycated haemoglobin (HbA1C) levels (OR 3.83, 95\% Cl 1.87 to 6.35).

Conclusions: There was a high prevalence of fundus pathology among patients with type 2 diabetes, and in most of the cases, this was newly detected. Community screening for fundus pathology among patients with a long duration of type 2 diabetes and high fasting plasma glucose and $\mathrm{HbA1c}$ levels using a telescreening model will provide an effective strategy for the prevention and treatment of fundus pathology.

\section{BACKGROUND}

Diabetes mellitus (DM) is known to affect vascular autoregulation and cause microvascular damage, especially in the retina and optic nerve. Many fundus pathologies such as retinopathy, glaucoma and age-related macular degeneration (AMD) are associated with DM. ${ }^{1-3}$ Screening would be very important for many patients with DM and early fundus pathology, which may be almost asymptomatic.

\section{Strengths and limitations of this study}

- This study described the telescreening model and assessed the prevalence of ocular fundus pathology among patients with type 2 diabetes mellitus within a healthcare centre in a Chinese urban community.

- In all participants, diagnoses were systematically ascertained using checking, and fundus diseases were measured according to standardised protocol by telescreening.

- As a community-based study, some diagnostic examinations were not performed to facilitate diagnosis.

- Because this was a baseline study, the sensitivity and cost-effectiveness analyses for this screening model need further investigation.

A recommended approach to the early detection of pathology is annual examinations of the ocular fundus. However, general practitioners (GPs) in Chinese communities do not normally or routinely check their patients for ocular fundus diseases, the retinal manifestations of diabetic retinopathy (DR) and retinal changes produced by other disorders.

The telescreening model includes digital fundus photography in participants attending the primary healthcare centre, and subsequent electronic transmission of these photographs to a reading centre for evaluation by professionals. The telescreening model has been used for screening of DR, and was performed in conjunction with a visit to the primary care physician, without referral to an ophthalmologist or optometrist. ${ }^{4}$ Telescreening has been confirmed as having the potential to improve compliance with other DR screening methods. ${ }^{5}$

This study was performed to assess the prevalence and risk factors for fundus pathology among patients with type 2 DM using telescreening in a Chinese community. 


\section{METHODS}

\section{Ethics statement}

This research was performed according to the principles of the Declaration of Helsinki, and written informed consent was obtained from the participants after explanation of the nature and possible consequences of the study.

\section{Patient recruitment}

The healthcare centre of Fengyutan community is a demonstration unit for the prevention and treatment model for diabetic eye disease at Liaoning Diabetic Eye Center. It provides health services for 80000 people in Fengyutan community in the Shenhe district of Shenyang city. A cross-sectional study was carried out among patients attending the Fengyutan Health Service. There were more than 1000 patients with DM attending the Fengyutan community healthcare centre, who were diagnosed in hospital according to the WHO criteria. The health files of patients over 45 years of age, with DM documented in hospital records or diagnosed during community clinic visits, were retrieved. Excluding ineligible patients with DM who had died, moved out of the community and were hospitalised or institutionalised in nursing homes, a total of $800(80 \%)$ patients were recruited by random sampling. Briefly, a total of 528 patients with type $2 \mathrm{DM}$ (mean age $55.09 \pm 3.18$ years, range 45-70) (response rate 66\%) participated in this study.

\section{Data collection and telescreening}

Name, age, smoking history, alcohol consumption and other health-related information of each participant were collected using a standardised questionnaire. Following an interview by a community worker, all participants were asked to fast overnight $(>8 \mathrm{~h})$ before a physical examination. All participants had their intraocular pressure (IOP) measured using a non-contact tonometer (NT-2000, NIDEK, Aichi, Japan). For all participants, two fundus photographs of each eye (the first focused on the macular fovea and the second focused on the optic centre) were taken by a well-trained general physician, using a $45^{\circ}$ non-mydriatic fundus camera (CR-DGi, Canon, Tokyo, Japan). The photographs were identified using questionnaire information and stored on a computer, and the general physician transmitted the photographs and participant information to the reading centre (Liaoning Diabetic Eye Center, Shenyang, China) by email. The photographs were used for diagnosis and grading, respectively, by two ophthalmologists. If there were differences, a third ophthalmologist was invited to read the photographs in order to ensure that the diagnosis was correct. After the photographs had been read, reports that included the results of the retinal assessment of the fundus photographs were sent to the GPs at the Fengyutan HealthCare Center and patients. The patients who needed treatment were referred to an ophthalmologist.
Laboratory methods

Blood was drawn from an antecubital vein in the morning after at least $8 \mathrm{~h}$ of fasting, for determination of total cholesterol, triglyceride and fasting plasma glucose levels and concentrations of glycated haemoglobin (HbA1c). All measurements were performed at the Endocrinology Laboratory, China Medical University, Shenyang, China, using commercially available assays.

Information from the questionnaire, physical examination, laboratory measurements and fundus pathology assessments was stored in a database.

\section{Definitions of DR, glaucoma, AMD and other factors}

DR was defined as the presence of any microaneurysms, haemorrhages, hard exudates, cotton-wool spots, intraretinal microvascular abnormalities and any neovascularisation or macular oedema. Sign of glaucoma was defined as an IOP $>21 \mathrm{~mm} \mathrm{Hg}$, a cup-disc ratio (CDR) greater than 0.60 , disc asymmetry with a CDR greater than 0.20 or known glaucoma. Sign of AMD was defined as large drusen and retinal pigment epithelial changes.

Smoking status was classified as not smoking (smoked $<100$ cigarettes in a patient's lifetime and currently not a smoker) and smoking (smoked $\geq 100$ cigarettes in a patient's lifetime regardless of whether the patient is currently a smoker). Alcohol consumption was defined as self-reported consumption of an average of more than $12 \mathrm{~g}$ of alcohol per day during the year before the examination among men and an average of more than $6 \mathrm{~g} /$ day among women. Hypertension was defined as an adult systolic blood pressure of $140 \mathrm{~mm} \mathrm{Hg}$ or greater or a diastolic blood pressure of $90 \mathrm{~mm} \mathrm{Hg}$ or greater. The length of time from the first diagnosis of DM was defined as duration of DM.

\section{Statistical analyses}

Statistical analyses were performed using the Statistical Package for the Social Sciences (SPSS) V.16.0 for Windows. $\chi^{2}$ Tests were used to compare the distributions of categorical variables and $t$ tests for unequal variances were used to compare continuous variables. Multivariate logistic regression models were used to estimate the ORs for fundus pathology. Potential confounders, including age and sex, were adjusted for, and the OR for fundus pathology was calculated. A $p$ value $<0.05$ was considered statistically significant.

\section{RESULTS}

As shown in table 1, there were 223 (42.23\%) patients with fundus pathology among the 528 patients with type 2 DM. There were 75 patients with DR, 63 with glaucoma, 57 with AMD and 28 with other pathologies. In most of these patients, except those with other pathologies, the fundus pathology was newly detected. The prevalence of DR $(14.20 \%)$ was somewhat higher than that of any of the other pathologies. 
Table 1 Categorisation of the different types of fundus pathology identified in 223 of the 528 patients with type 2 diabetes mellitus*

\begin{tabular}{lcc}
\hline Fundus pathology & $\begin{array}{c}\text { Number of } \\
\text { patients (\%) }\end{array}$ & $\begin{array}{l}\text { Number of patients with } \\
\text { newly detected pathology (\%) }\end{array}$ \\
\hline Signs of DR & $75(14.20)$ & $65(86.67)$ \\
Signs of glaucoma & $63(11.93)$ & $53(84.13)$ \\
Signs of AMD & $57(10.79)$ & $48(84.21)$ \\
Sign of DR and glaucoma & $9(1.70)$ & $6(66.67)$ \\
Sign of DR and AMD & $6(1.13)$ & $6(100)$ \\
Sign of glaucoma and AMD & $2(0.38)$ & $2(100)$ \\
Sign of DR, glaucoma and AMD & $1(0.19)$ & $1(100)$ \\
Other pathology (including pathological myopia, & $28(5.30)$ & $9(32.14)$ \\
retinal vessel occlusion, optic nerve atrophy, macular hole, etc) & & \\
\hline *Some patients may have had more than one fundus pathology. & & \\
AMD, age-related macular degeneration; DR, diabetic retinopathy. & &
\end{tabular}

As shown in table 2, most of the patients with fundus pathology had DM for 6-15 years, and they also had higher total cholesterol and HbA1c levels $(\mathrm{p}<0.01)$. Most of the patients with DR were aged 55-64 years, and had hypertension and higher HbAlc levels $(\mathrm{p}<0.01)$.
Among the patients with glaucoma, $65.79 \%$ were women, and most of these patients were aged 5564 years and also had higher IOPs $(p<0.01)$. More than half of the patients with AMD were older than 65 years, and were smokers with a long duration of DM $(\mathrm{p}<0.01)$.

Table 2 Demographic and clinical characteristics of the 528 patients with type 2 DM

\begin{tabular}{|c|c|c|c|c|c|}
\hline & $\begin{array}{l}\text { All } \\
\text { participants }\end{array}$ & $\begin{array}{l}\text { All patients with } \\
\text { fundus pathology }\end{array}$ & $\begin{array}{l}\text { Patients with } \\
\text { signs of DR }\end{array}$ & $\begin{array}{l}\text { Patients with } \\
\text { signs of glaucoma }\end{array}$ & $\begin{array}{l}\text { Patients with } \\
\text { signs of AMD }\end{array}$ \\
\hline Age (years), n (\%) & 528 & 223 (42.23) & 75 (14.20) & 63 (11.93) & 57 (10.79) \\
\hline $45-54$ & 186 (35.23) & $71(31.84)$ & 32 (33.33) & 19 (30.16) & 11 (19.30) \\
\hline $55-64$ & $224(42.42)$ & 89 (39.91) & $36(57.33)$ & $32(50.79)$ & $14(24.56)$ \\
\hline$>65$ & 118 (22.35) & $63(28.25)$ & $7(9.33)$ & $12(19.05)$ & $32(56.14)$ \\
\hline \multicolumn{6}{|l|}{ Sex, n (\%) } \\
\hline Females & $287(54.36)$ & $118(52.91)$ & $44(58.67)$ & $41(65.79)$ & $25(43.86)$ \\
\hline Males & 241 (45.64) & 105 (47.09) & 31 (41.33) & $22(34.21)$ & $32(56.14)$ \\
\hline \multicolumn{6}{|l|}{ Smoking, n (\%) } \\
\hline Yes & 309 (58.52) & $128(57.34)$ & $42(56)$ & $31(49.21)$ & 37 (64.91) \\
\hline No & 219 (41.48) & $95(42.66)$ & $33(44)$ & $32(50.79)$ & 20 (35.09) \\
\hline \multicolumn{6}{|c|}{ Alcohol consumption, $\mathrm{n}(\%)$} \\
\hline Yes & 359 (67.99) & $119(53.36)$ & $36(48)$ & $29(46.03)$ & $26(45.61)$ \\
\hline No & 169 (32.01) & 104 (46.64) & $39(52)$ & $34(53.97)$ & 31 (54.39) \\
\hline \multicolumn{6}{|c|}{ Duration of DM (years), $\mathrm{n}(\%)$} \\
\hline$<5$ & $184(34.85)$ & $59(26.46)$ & $19(25.33)$ & $17(26.98)$ & $16(28.07)$ \\
\hline $6-15$ & $220(41.67)$ & $91(40.81)$ & $24(32)$ & 21 (33.33) & $17(29.82)$ \\
\hline$>16$ & $118(22.35)$ & 73 (32.73) & $32(42.67)$ & 25 (39.69) & $24(42.11)$ \\
\hline \multicolumn{6}{|l|}{ Hypertension, n (\%) } \\
\hline Present & $365(69.13)$ & $112(50.22)$ & $49(65.33)$ & $28(44.44)$ & $29(50.88)$ \\
\hline Absent & $163(30.87)$ & $111(49.78)$ & $26(34.67)$ & $35(55.56)$ & $28(49.12)$ \\
\hline \multicolumn{6}{|l|}{ DM controlled, n (\%) } \\
\hline Yes & 315 (59.66) & 132 (59.19) & $41(54.67)$ & $38(60.32)$ & 31 (54.39) \\
\hline No & 213 (40.34) & $91(40.81)$ & 34 (45.33) & 25 (39.68) & $26(45.61)$ \\
\hline $\mathrm{IOP}, \mathrm{mm} \mathrm{Hg}$, mean $\pm \mathrm{SD}$ & $18.87 \pm 5.78$ & $19.76 \pm 3.54$ & $18.15 \pm 2.94$ & $25.33 \pm 3.19$ & $16.91 \pm 2.15$ \\
\hline $\mathrm{FPG}, \mathrm{mmol} / \mathrm{L}, \mathrm{mean} \pm \mathrm{SD}$ & $8.96 \pm 2.34$ & $9.92 \pm 4.33$ & $11.03 \pm 3.37$ & $8.02 \pm 2.43$ & $8.45 \pm 1.18$ \\
\hline $\mathrm{TG}, \mathrm{mmol} / \mathrm{L}$, mean $\pm \mathrm{SD}$ & $1.89 \pm 0.65$ & $1.94 \pm 0.56$ & $1.98 \pm 0.54$ & $1.66 \pm 0.44$ & $1.81 \pm 0.32$ \\
\hline $\mathrm{TC}, \mathrm{mmol} / \mathrm{L}$, mean $\pm \mathrm{SD}$ & $5.27 \pm 1.78$ & $6.02 \pm 1.34$ & $5.89 \pm 1.21$ & $5.09 \pm 1.01$ & $4.99 \pm 1.44$ \\
\hline $\mathrm{HbA1c}(\%)$ & 7.99 & 11.92 & 12.21 & 6.01 & 5.98 \\
\hline
\end{tabular}


Table 3 Risk factors for fundus pathology in patients with type 2 DM as assessed by logistic regression analysis

\begin{tabular}{|c|c|c|c|c|c|c|c|c|}
\hline & $\begin{array}{l}\text { All patients with } \\
\text { fundus pathology } \\
\text { OR }(95 \% \mathrm{Cl})\end{array}$ & p Value & $\begin{array}{l}\text { Patients with } \\
\text { signs of DR } \\
\text { OR }(95 \% \mathrm{Cl})\end{array}$ & p Value & $\begin{array}{l}\text { Patients with signs } \\
\text { of glaucoma } \\
\text { OR }(95 \% \mathrm{CI})\end{array}$ & p Value & $\begin{array}{l}\text { Patients with } \\
\text { signs of AMD } \\
\text { OR }(95 \% \mathrm{Cl})\end{array}$ & p Value \\
\hline Age (years) & - & - & & & & & & \\
\hline $45-54$ & 1.00 & & 1.00 & & 1.00 & & 1.00 & \\
\hline $55-64$ & 0.79 (0.51 to 1.12$)$ & 0.06 & $0.52(0.21$ to 0.78$)$ & 0.01 & $1.08(0.35$ to 1.71$)$ & 0.06 & 0.79 (0.63 to 0.86$)$ & $<0.001$ \\
\hline$>65$ & 1.21 (0.91 to 1.98$)$ & 0.07 & 0.48 (0.32 to 0.52$)$ & 0.02 & $1.52(0.71$ to 2.78$)$ & 0.07 & 1.29 (1.11 to 1.32$)$ & $<0.001$ \\
\hline \multicolumn{9}{|l|}{ Sex } \\
\hline Females & 1.00 & & 1.00 & & 1.00 & & 1.00 & \\
\hline Males & $0.68(0.53$ to 0.73$)$ & 0.01 & 0.78 (0.62 to 0.84$)$ & 0.01 & $0.53(0.42$ to 0.61$)$ & $<0.001$ & 0.61 (0.54 to 0.71$)$ & 0.01 \\
\hline \multicolumn{9}{|l|}{ Smoking } \\
\hline No & 1.00 & & 1.00 & & 1.00 & & 1.00 & \\
\hline Yes & 0.89 (0.82 to 1.02$)$ & 0.06 & 2.88 (1.79 to 3.91$)$ & $<0.001$ & $1.88(0.62$ to 2.31$)$ & 0.10 & $1.18(0.87$ to 1.38$)$ & 0.07 \\
\hline \multicolumn{9}{|c|}{ Alcohol consumption } \\
\hline No & 1.00 & & 1.00 & & 1.00 & & 1.00 & \\
\hline Yes & $1.12(0.86$ to 1.31$)$ & 0.06 & 1.98 (1.49 to 2.96$)$ & $<0.001$ & $0.97(0.62$ to 1.34$)$ & 0.06 & $2.08(0.97$ to 3.93$)$ & 0.01 \\
\hline \multicolumn{9}{|c|}{ Duration of DM (years) } \\
\hline$<5$ & 1.00 & & 1.00 & & 1.00 & & 1.00 & \\
\hline $6-15$ & 1.98 (1.29 to 2.97$)$ & $<0.001$ & 1.93 (1.39 to 2.87$)$ & $<0.001$ & 1.28 (1.09 to 1.47$)$ & 0.003 & 1.19 (1.02 to 1.37$)$ & $<0.001$ \\
\hline$>16$ & 2.31 (1.87 to 2.56$)$ & $<0.01$ & 2.45 (1.65 to 3.16$)$ & $<0.01$ & $0.99(0.87$ to 1.16$)$ & 0.07 & 2.31 (1.87 to 2.56$)$ & 0.01 \\
\hline \multicolumn{9}{|l|}{ Hypertension } \\
\hline No & 1.00 & & 1.00 & & 1.00 & & 1.00 & \\
\hline Yes & $1.18(0.97$ to 1.54$)$ & 0.06 & $1.32(1.29$ to 1.66$)$ & 0.001 & 2.18 (1.39 to 2.94$)$ & 0.03 & $0.81(0.49$ to 1.34$)$ & 0.10 \\
\hline \multicolumn{9}{|c|}{ DM controlled } \\
\hline No & 1.00 & & 1.00 & & 1.00 & & 1.00 & \\
\hline Yes & 1.84 (0.88 to 2.35$)$ & 0.21 & $1.12(0.38$ to 2.15$)$ & 0.12 & 1.14 (0.58 to 2.23$)$ & 0.14 & $0.92(0.55$ to 1.55$)$ & 0.09 \\
\hline \multicolumn{9}{|c|}{$\mathrm{IOP}>21 \mathrm{~mm} \mathrm{Hg}$} \\
\hline No & 1.00 & & 1.00 & & 1.00 & & 1.00 & \\
\hline Yes & 1.85 (0.38 to 3.15$)$ & 0.21 & $1.21(0.56$ to 1.75$)$ & 0.11 & 3.84 (2.85 to 4.66$)$ & 0.01 & $0.89(0.81$ to 1.25$)$ & 0.23 \\
\hline \multicolumn{9}{|c|}{$\mathrm{FPG}>7 \mathrm{mmol} / \mathrm{L}$} \\
\hline No & 1.00 & & 1.00 & & 1.00 & & 1.00 & \\
\hline Yes & $3.64(1.81$ to 5.21$)$ & $<0.001$ & 2.55 (1.85 to 4.15$)$ & 0.03 & $1.81(0.82$ to 3.15$)$ & 0.22 & $2.82(0.58$ to 4.54$)$ & 0.28 \\
\hline \multicolumn{9}{|c|}{$\mathrm{TG}>1.7 \mathrm{mmol} / \mathrm{L}$} \\
\hline No & 1.00 & & 1.00 & & 1.00 & & 1.00 & \\
\hline Yes & $0.83(0.55$ to 1.38$)$ & 0.08 & $1.54(0.78$ to 2.33$)$ & 0.07 & 1.31 (0.96 to 1.67$)$ & 0.09 & $3.83(0.25$ to 6.15$)$ & 0.26 \\
\hline \multicolumn{9}{|c|}{$\mathrm{TC}>5.5 \mathrm{mmol} / \mathrm{L}$} \\
\hline No & 1.00 & & 1.00 & & 1.00 & & 1.00 & \\
\hline Yes & $2.24(0.75$ to 3.15$)$ & 0.11 & $1.11(0.55$ to 2.44$)$ & 0.18 & 0.89 (0.51 to 2.42$)$ & 0.27 & 1.14 (0.66 to 2.37$)$ & 0.21 \\
\hline \multicolumn{9}{|l|}{$\mathrm{HbA} 1 \mathrm{c}>7 \%$} \\
\hline No & 1.00 & & 1.00 & & 1.00 & & 1.00 & \\
\hline Yes & $3.83(1.87$ to 6.35$)$ & $<0.001$ & $3.12(1.18$ to 7.15$)$ & 0.001 & $1.12(1.08$ to 1.75$)$ & 0.01 & $1.22(1.01$ to 1.73$)$ & 0.02 \\
\hline
\end{tabular}


Table 4 Studies that have investigated the prevalence of fundus pathology in patients with type 2 DM in urban or community settings

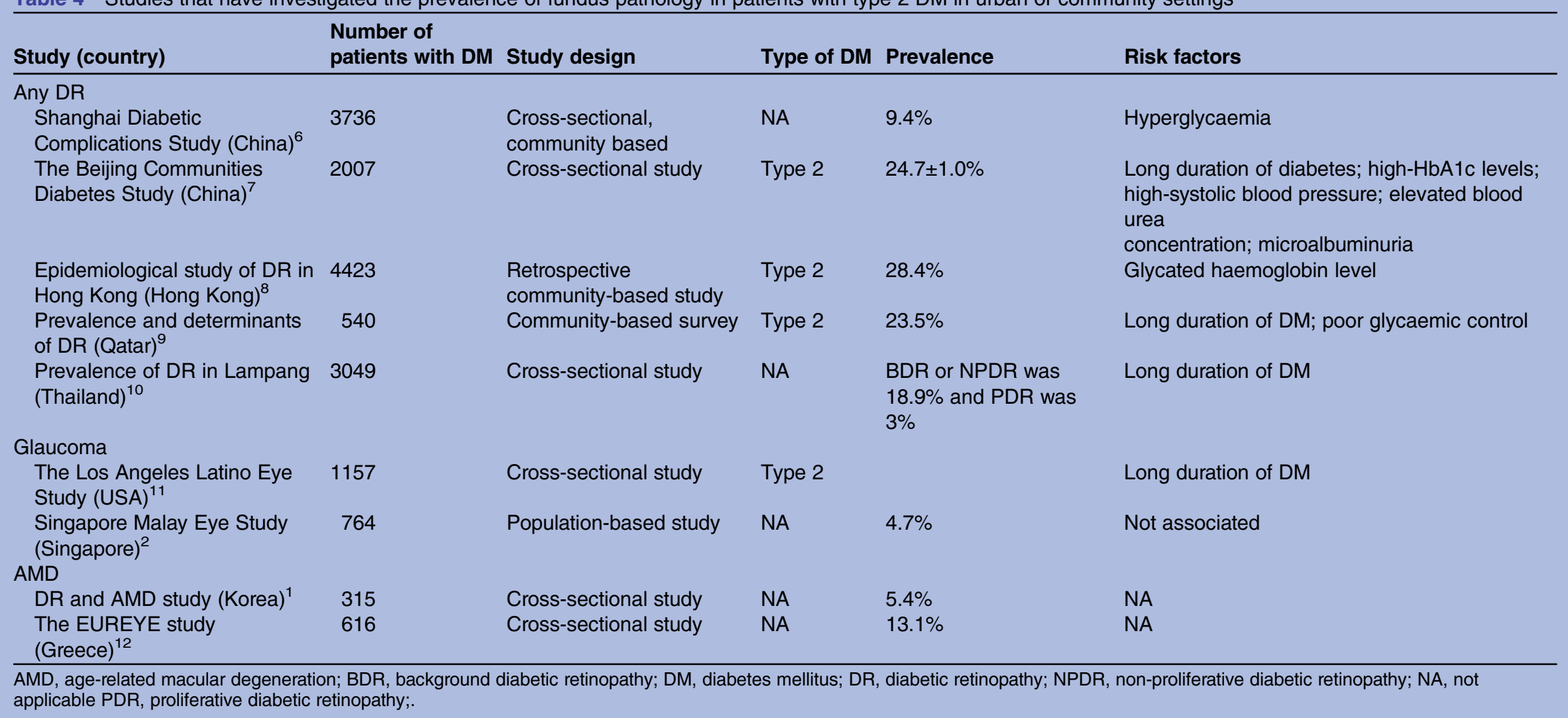


Longer duration of DM (OR 2.31, 95\% CI 1.87 to 2.56) and higher fasting plasma glucose (OR 3.64, 95\% CI 1.81 to 5.21) and HbAlc levels (OR 3.83, 95\% CI 1.87 to 6.35 ) were risk factors for fundus pathology after adjustment for age and sex, as shown in table 3 . Smoking (OR, 1.12; 95\% CI 0.86 to 1.31 ) and alcohol consumption (OR, 0.89 ; 95\% CI 0.82 to 1.02 ) were no longer the significant risk factors for fundus pathology in all patients. However, the risk factors were smoking, alcohol consumption, long duration of DM and high fasting plasma glucose and HbAlc levels for patients with only signs of DR. The likelihood of developing glaucoma was increased in type $2 \mathrm{DM}$ patients with hypertension and high IOPs or HbAlc levels. The risk factors for AMD were age, long duration of DM and high HbAlc levels.

\section{DISCUSSION}

In this cross-sectional study, we used a new telescreening model to identify fundus pathology among patients attending a community healthcare centre. The study showed that among 528 patients with type 2 DM, 223 (42.23\%) had fundus pathology, and the risk factors for fundus pathology were long duration of DM and high fasting plasma glucose and HbAlc levels. Attention should be focused on long duration of DM and high HbA1c levels, which were the risk factors for all three fundus pathologies in this study. The results showed that the prevalence of fundus pathology was high, and that the risk factors, especially HbAlc levels, should be controlled. Table 4 shows the results of selected studies on the prevalence of fundus pathologies among patients with type $2 \mathrm{DM}$ in urban or community settings. In the present study, $75(14.20 \%)$ patients among the 528 with type 2 DM showed signs of DR, which was lower than the prevalence in a Beijing study ${ }^{7}$; this difference may be explained by the younger age of participants in the present study.

Glaucoma was the second most frequent fundus pathology identified in this study, with $63(11.93 \%)$ patients being affected. Previous study reported that genetic factors such as the endothelial NO synthase (Glu298Asp) polymorphism might play a role in diabetic patients with glaucoma. ${ }^{13}$ However, we also need further research to investigate the relationship between glaucoma and DM.

AMD, which is an age-related fundus disease, was observed in 57 patients $(10.79 \%)$ with type $2 \mathrm{DM}$. This phenomenon may be the result of both oxidation and a decline in pool size. ${ }^{14}$

Because most of the fundus pathologies were newly detected, early screening would appear to be very important, and patients with DM should be screened for fundus pathology regularly. Early screening has the potential to significantly improve final visual outcomes in patients who develop subfoveal choroidal neovascularisation associated with AMD. ${ }^{15}$ Apart from its clinical significance, the economic impact of early screening could also be very significant. ${ }^{16}$ For early screening, there must be an effective and easily implementable screening model that is appropriate for conditions in China. Recently, Peng et al ${ }^{17}$ established a telescreening system for detecting DR in the Shanghai Beixinjing community. In this study, we identified patients and used email to transmit the data for reading, in order to ensure secure and timely communication. At the same time, we analysed the risk factors for fundus pathology associated with DM and established a database of all screened patients for prospective research.

\section{Limitations of the study}

Despite the conclusive results that were obtained from this study, there were some shortcomings that should be noted. First, this was a community-based study of patients attending a community healthcare centre; therefore fundus fluorescein angiography or visual field and optical coherence tomography were not performed to facilitate diagnosis. Second, only few participants were enrolled because a new screening model was used. Third, because this was a baseline study, the sensitivity and cost-effectiveness analyses for this screening model are still in progress. Fourth, we cited a number of studies in table 4 . The number of fundus photographs taken, assessment method, diagnostic criteria and grading classification used for DR, glaucoma and AMD in this study may not be directly comparable to those used in the various cited studies. This could result in over-estimation or under-estimation of the true prevalence of DR, glaucoma and AMD in this study versus that of other studies. In addition, the $\kappa$ statistic for two ophthalmologists diagnosis is not worked out; this should be studied in further research.

We believe this study is helpful for better understanding of the prevalence and risk factors for fundus pathology in patients with type $2 \mathrm{DM}$.

Acknowledgements This study was supported by Liaoning Diabetic Eye Center and the Liaoning Provincial Key Laboratory of Endocrine Diseases, and the Endocrine Institute of China Medical University. The authors thank Fengping Shan, PhD, Professor of Immunology, China Medical University and Xiaomei Wu, Master of Medicine, Department of Clinical Epidemiology, First Affiliated Hospital of China Medical University.

Contributors $\mathrm{LL}$ and $\mathrm{LC}$ conceived and designed the experiments, they also wrote the manuscript. LL, JL, JG, ZY and LC performed the experiments. LL, JW and HD analysed the data. LL and ZY contributed by gathering reagents/ materials/analysis tools.

Funding This research received no specific grant from any funding agency in the public, commercial or not-for-profit sectors.

Competing interests None.

Patient consent Obtained.

Ethics approval The research was approved by the Institutional Ethics Committee of China Medical University (2011080312).

Provenance and peer review Not commissioned; externally peer reviewed. Data sharing statement No additional data are available. 
Open Access This is an Open Access article distributed in accordance with the Creative Commons Attribution Non Commercial (CC BY-NC 3.0) license, which permits others to distribute, remix, adapt, build upon this work noncommercially, and license their derivative works on different terms, provided the original work is properly cited and the use is non-commercial. See: http:// creativecommons.org/licenses/by-nc/3.0/

\section{REFERENCES}

1. Choi JK, Lym YL, Moon JW, et al. Diabetes mellitus and early age-related macular degeneration. Arch Ophthalmol 2011;129:196-9.

2. Tan GS, Wong TY, Fong CW, et al. Diabetes, metabolic abnormalities, and glaucoma. Arch Ophthalmol 2009;127:1354-61.

3. Zheng Y, Wong TY, Cheung CY, et al. Influence of diabetes and diabetic retinopathy on the performance of Heidelberg retina tomography II for diagnosis of glaucoma. Invest Ophthalmol Vis Sci 2010;51:5519-24

4. Villena JE, Yoshiyama CA, Sánchez JE, et al. Prevalence of diabetic retinopathy in Peruvian patients with type 2 diabetes: results of a hospital-based retinal telescreening program. Rev Panam Salud Publica 2011;30:408-14.

5. Stefánsson E, Bek T, Porta M, et al. Screening and prevention of diabetic blindness. Acta Ophthalmol Scand 2000;78:374-85.

6. Pang C, Jia L, Jiang S, et al. Determination of diabetic retinopathy prevalence and associated risk factors in Chinese diabetic and pre-diabetic subjects: Shanghai Diabetic Complications Study. Diabetes Metab Res Rev 2011;28:276-83.

7. $\mathrm{Xu} \mathrm{J}$, Wei WB, Yuan MX, et al. Prevalence and risk factors for diabetic retinopathy: the Beijing Communities Diabetes Study 6 . Retina 2012;32:322-9.
8. Tam TK, Lau CM, Tsang LC, et al. Epidemiological study of diabetic retinopathy in a primary care setting in Hong Kong. Hong Kong Med J 2005;11:438-44.

9. Elshafei M, Gamra H, Khandekar R, et al. Prevalence and determinants of diabetic retinopathy among persons $\geq 40$ years of age with diabetes in Qatar: a community-based survey. Eur $J$ Ophthalmol 2011;21:39-47.

10. Jenchitr W, Samaiporn S, Lertmeemongkolchai $P$, et al. Prevalence of diabetic retinopathy in relation to duration of diabetes mellitus in community hospitals of Lampang. J Med Assoc Thai 2004;87:1321-6.

11. Chopra V, Varma R, Francis BA, et al. Type 2 diabetes mellitus and the risk of open-angle glaucoma the Los Angeles Latino Eye Study. Ophthalmology 2008;115:227-32.e1.

12. Topouzis F, Anastasopoulos E, Augood C, et al. Association of diabetes with age-related macular degeneration in the EUREYE study. Br J Ophthalmol 2009;93:1037-41.

13. Hermans MP, Ahn SA, Rousseau MF. eNOS [Glu298Asp] polymorphism, erectile function and ocular pressure in type 2 diabetes. Eur J Clin Invest 2012;42:729-37.

14. Samiec PS, Drews-Botsch C, Flagg EW, et al. Glutathione in human plasma: decline in association with aging, age-related macular degeneration, and diabetes. Free Radic Biol Med 1998;24:699-704.

15. Loewenstein A; Richard \& Hinda Rosenthal Foundation. The significance of early detection of age-related macular degeneration: Richard \& Hinda Rosenthal Foundation Lecture, The Macula Society 29th Annual Meeting. Retina 2007;27:873-8.

16. Javitt JC, Zhou Z, Willke RJ. Association between vision loss and higher medical care costs in Medicare beneficiaries are greater for those with progressive vision loss. Ophthalmology 2007;114: 238-45.

17. Peng J, Zou H, Wang W, et al. Implementation and first-year screening results of an ocular telehealth system for diabetic retinopathy in China. BMC Health Serv Res 2011;11:250. 